\title{
O ACORDO DE PARIS E A MUDANÇA PARADIGMÁTICA DE APLICAÇÃO DO PRINCÍPIO DA RESPONSABILIDADE COMUM, PORÉM DIFERENCIADA
}

\author{
Maria Clara de Jesus Maniçoba Balduino ${ }^{73}$
}

\begin{abstract}
RESUMO
Com a evolução do contexto internacional de regulamentação climática, a sociedade internacional percebeu que o modelo bipartido de responsabilização adotado até então não refletia a máxima do "princípio da responsabilidade comum, porém diferenciada". Nesse contexto, o presente estudo analisa como o Acordo de Paris traz abordagem inovadora a partir da instituição das Contribuições Nacionalmente Determinadas que reflete as circunstâncias nacionais de cada Parte. Utiliza como procedimentos metodológicos a pesquisa exploratória e bibliográfica, com consulta a meio impresso e eletrônico. Ademais, a pesquisa é do tipo qualitativa, a qual visa analisar o aspecto subjetivo do tema, buscando investiga-lo sob um olhar mais crítico. Conclui-se que foi preciso alterar o paradigma tradicional do regime climático internacional para uma efetiva inclusão de todos os membros da sociedade internacional no contexto de mitigação dos efeitos das mudanças do clima.
\end{abstract}

Palavras-chave: Responsabilidade diferenciada. Mudanças Climáticas. Acordo de Paris

\section{INTRODUÇÃO}

Ao longo dos anos, a sociedade internacional vislumbrou a necessidade de mobilizar-se em prol da proteção ambiental, culminando com a produção de diversos documentos tais como tratados e acordos internacionais direcionados à normatização da proteção do ar, do mar, dos ecossistemas naturais e do uso da terra, pautados sob um viés de sustentabilidade e justiça socioambiental à luz das responsabilidade comuns, porém diferenciadas, de cada nação.

\footnotetext{
${ }^{73}$ Mestranda em Direito pela Universidade Federal do Rio Grande do Norte (UFRN). Pesquisadora (CAPES). Advogada. Especialista em Direito Previdenciário pela Universidade do Estado do Rio Grande do Norte (UERN). Técnica em Controle Ambiental pelo Instituto Federal de Educação, Ciência e Tecnologia do Rio Grande do Norte (IFRN).
} 
A Convenção-Quadro das Nações Unidas sobre Mudança do Clima (CQNUMC) tratou de dividir o planeta em dois grandes hemisférios, um grupo de países considerados desenvolvidos e que em regra emitem uma maior quantidade de gases poluentes, e os países em desenvolvimento, cujas condições especiais devem ser observadas na implementação das medidas atinentes à Convenção.

No âmbito da CQNUMC, o Acordo de Paris surge com a missão de rearranjar um novo paradigma de governança global para combater os efeitos das mudanças climáticas com o estabelecimento de novas metas de redução de gases de efeito estufa e uma abordagem diferenciada na execução de tais metas, com as denominadas Contribuições Nacionalmente Determinadas.

O Acordo de Paris, trouxe as denominadas "Contribuições Pretendidas Nacionalmente Determinadas" (CNDs) em sua redação, que deverão ser desenvolvidas no âmbito de cada um dos Estados-Partes, cada qual refletindo sua parcela de responsabilidade. Trata-se de uma abordagem diferenciada do modelo de responsabilização bipartido adotado até então, entregando à soberania de cada ente, a incumbência de formular e determinar suas próprias metas à luz de suas capacidades nacionais.

Diante do exposto, o objetivo principal do presente estudo é analisar a nova conjectura de regulamentação internacional rompe com o modelo tradicional bipartite de responsabilização dos Estados-Parte pela emissão de gases de efeito estufa, e passa a considerar a unicidade da comunidade internacional, e responsabilização coletiva à luz do contexto nacional de cada um. Para isso, a discussão dos objetivos específicos considerará o contexto histórico evolutivo da abordagem do princípio da responsabilidade comum porém diferenciada desde a Convenção Quadro das Nações Unidas ao Acordo de Paris; partindo-se à análise da abordagem diferencial Bottom-Up assumida pelas Contribuições Nacionalmente Determinadas no âmbito do referido documento; por fim, verificando a aplicabilidade do Acordo de Paris em razão do status (não) vinculativo desses compromissos nacionais assumidos pelas Partes.

A metodologia empregada baseia-se na pesquisa exploratória e bibliográfica em com consulta à doutrina especializada, nacional e estrangeira, onde assunto proposto possui maior exploração acadêmica, tendo em vista que se trata de tema atual cujos elementos encontram-se em constante construção. Ademais, a pesquisa é do tipo qualitativa, a qual visa analisar o aspecto subjetivo do tema, buscando investiga-lo sob um olhar mais crítico. 


\section{HISTÓRICO-EVOLUTIVO DO RECONHECIMENTO DAS RESPONSABILIDADES COMUNS POREM DIFERENCIADAS}

O princípio da "responsabilidade comum, porém diferenciada" é princípio basilar do regimento internacional de mudanças climáticas, previsto desde o lançamento da Convenção Quadro das Nações Unidas sobre Mudança do Clima (CQNUMC). O referido princípio reflete a ideia de "justiça climática", ao esculpir a o conceito de responsabilidade atrelado à parcela de imputabilidade cabível a cada Estado, tomando por base o nível de emissões, desenvolvimento, capacidade contributiva (tecnológica e socioeconômica) e contexto nacional.

Assim, a CQNUMC previa em sua parte introdutória, a inferência da responsabilidade comum porém diferenciada, em associação com o princípio da equidade intergeracional, ao aduzir que as Partes deveriam proteger o sistema climático em benefício das gerações presentes e futuras da humanidade, tomando por base, cada um, sua parcela de responsabilidade, conforme as respectivas capacidades.

Esse princípio é conjecturado e irradiado aos protocolos e programas seguintes desenvolvidos no âmbito da Convenção, como por exemplo o Protocolo de Quioto, e posteriormente o Acordo de Paris, que carregam o princípio de forma expressa em seu documento.

\section{O PRINCÍPIO DA RESPONSABILIDADE COMUM, PORÉM DIFERENCIADA NA CONVENÇÃO QUADRO DAS NAÇÕES UNIDAS SOBRE MUDANÇA DO CLIMA}

A Conferência das Nações Unidas para o Meio Ambiente e o Desenvolvimento (CNUMAD) realizada no Rio de Janeiro em 1992, representou um divisor de águas no que diz respeito à conscientização das nações acerca da fragilidade do ambiente em que vivemos, desenvolvendo-se a ideia de que o ser humano tem direito ao um ambiente sadio, e em equilíbrio com a natureza.

$\mathrm{Na}$ Conferência estiveram presentes 178 delegações, inclusive chefes de estado ou de governo, de 115 países. A assinatura da Convenção-Quadro das Nações Unidas sobre Mudança do Clima abriu margem para o contexto internacional de regulamentação das mudanças climáticas, 
tendo entrado em vigor no dia 21 de março de 1994, noventa dias após a data de depósito do quinquagésimo instrumento de ratificação, aceitação, aprovação ou adesão, conforme previa o art. 23.2 da Convenção (NAÇÕES UNIDAS ${ }^{1}$, 2020). A Convenção conta hoje com 197 Partes, o que representa uma participação quase universal (EUROPEAN COMISSION, 2020). O Brasil foi o primeiro país a assinar a Convenção Quadro das Nações Unidas sobre Mudança do Clima que foi definitivamente incorporada ao ordenamento jurídico interno, com abrangência em todo território nacional, por meio do Decreto $n^{\circ} 2.652$, de $1^{\circ}$ de julho de 1998 (MINISTÉRIO DO MEIO AMBIENTE $\left.^{3}, 2020\right)$

A Convenção-Quadro das Nações Unidas sobre Mudanças Climáticas (em inglês, United Nations Framework Convention on Climate Change ou UNFCCC) tem o objetivo de estabilizar as concentrações de gases de efeito estufa na atmosfera em um nível que impeça uma interferência humana perigosa no sistema climático. $\mathrm{O}$ documento prevê que esse nível deverá ser alcançado em um prazo suficiente que permita aos ecossistemas adaptarem-se naturalmente à mudança do clima, assegurando que a produção de alimentos não seja ameaçada e permitindo ao desenvolvimento econômico prosseguir de maneira sustentável (MINISTÉRIO DO MEIO AMBIENTE¹, 2020).

O escopo da Convenção foi estabelecer metas de redução de gases causadores do efeito estufa a partir da divisão dos estados parte em dois grandes blocos, dos países desenvolvidos e países em desenvolvimento. Desde sua parte introdutória, a Convenção ressalta necessidade de liderança dos países desenvolvidos na trajetória de mitigação dos efeitos do clima, apontando que essa responsabilidade lhes é cabível em razão da maior parte das emissões globais que lhes são imputadas:

Observando que a maior parcela das emissões globais, históricas e atuais, de gases de efeito estufa é originária dos países desenvolvidos, que as emissões per capita dos países em desenvolvimento ainda são relativamente baixas e que a parcela de emissões globais originárias dos países em desenvolvimento crescerá para que eles possam satisfazer suas necessidades sociais e de desenvolvimento ${ }^{74}$.

O artigo terceiro, que expõe os princípios que regem a Convenção, destaca em seu parágrafo segundo as necessidades específicas e circunstâncias especiais dos países em desenvolvimento, que os tornam mais suscetíveis aos efeitos das mudanças do clima, ressaltando que este grupo de

\footnotetext{
${ }^{74}$ BRASIL. DECRETO No 2.652, DE $1^{\circ}$ DE JULHO DE 1998. Promulga a Convenção-Quadro das Nações Unidas sobre Mudança do Clima, assinada em Nova York, em 9 de maio de 1992. Brasília, Disponível em: http://www.planalto.gov.br/ccivil_03/decreto/d2652.htm. Acesso em: 25 mai. 2020
} 
estados-partes não devem assumir encargos desproporcionais e anormais sob esta Convenção. Em regra, historicamente considerados os mais vulneráveis aos efeitos negativos provocados pela mudança do clima, seja pela escassez de tecnologias eficientes de combate a esses efeitos, seja pela limitação socioeconômica de implementação de políticas públicas voltadas à educação ambiental (HUQ; REID; KONATE; RAHMAN; SOKONA; CRICK, 2011, p. 25).

O princípio da "responsabilidade comum, mas diferenciada", aduz a ideia de que todos devem cooperar em prol da preservação no direito internacional do meio ambiente, mas levandose em consideração à capacidade nacional de cada um, em razão de seu nível de desenvolvimento e poderia socioeconômico no cenário internacional. Por esta razão, historicamente se atribui maior responsabilidade aos países desenvolvidos, por se vislumbrar maiores condições econômicas, e estabilidade para se instituir as políticas ambientais de redução de emissões de gases (MOTTA, 2011, p. 12).

Os países menos desenvolvidos são os mais susceptíveis às reações calamitosas dos impactos das mudanças climáticas, devido a fatores físicos, sociais e econômicos, além da lacuna no conhecimento científico e patentes de tecnologias climáticas. A grande a maioria das patentes em todo o mundo é detida por empresas com sede na América do Norte, Europa e Japão. Nas tecnologias ambientais voltadas à mitigação de efeitos do clima, os países desenvolvidos também detêm a maior parte dessas patentes em todo o mundo. Em 2005, os países da União Europeia detinham 36,7\% das patentes vinculadas a energia renovável, com os EUA detendo 20,2\% e o Japão 19,8\%, enquanto a China detinha 2,9\% e Coreia 2,3\% (KHOR, 2012, p. 6).

Ademais, vulnerabilidade biofísica nos países menos desenvolvidos causam efeitos adversos na segurança alimentar, saúde humana, biodiversidade, recursos hídricos, hidrelétricas, geração de energia, córregos, nascentes perenes e meios de subsistência (MIYAN, 2015, p. 8).

Importantes organizações internacionais, incluindo o Bando Mundial, a Organização Internacional de Cooperação e Desenvolvimento, e o Secretariado do da Convenção Quadro das Nações Unidas sobre Mudança do Clima avaliaram os custos de adaptação às mudanças climáticas nos países em desenvolvimento. Com base em uma ampla gama de estudos de caso setoriais e nacionais, suas estimativas variam de US\$9 bilhões a US\$ 100 bilhões de dólares anuais. O secretariado da UNFCCC, por exemplo, estimou despesas anuais de adaptação até 2030 em seis áreas: agricultura, pesca e silvicultura (US\$ 14 bilhões); recursos hídricos (US\$11bilhão); saúde humana (US \$ 4-5 bilhões); ecossistemas (US \$ 12 a 22 bilhões); zonas costeiras (US \$ 11 bilhões); 
e infraestrutura (US \$ 8-130 bilhões) estimados (PATT; TARDROSS; NUSSBAUMER; ASSANTE; METZGER; RAFAEL; GOUJON; BRUNDRIT, 2010, p. 1333).

Por este motivo a Convenção-Quadro das Nações Unidas sobre Mudança do Clima reconhece a necessidade de adoção de medidas mais austeras pelos países desenvolvidos (artigo 4.2), ao contraponto em que perfilha as circunstancias especiais dos países em desenvolvimento em virtude de sua situação de progresso econômico, quanto a persecução das medidas para limitação de emissões de gases de efeito estufa (artigo 4.3) ${ }^{75}$.

$\mathrm{Na}$ Convenção foram estabelecidos compromissos e obrigações a todas as partes em seu artigo 4, pontuando de forma expressa que se darão "levando em conta suas responsabilidades comuns mas diferenciadas e suas prioridades de desenvolvimento" tais como: elaborar inventários nacionais de emissões de gases de efeito estufa; incentivo ao desenvolvimento e divulgação de novas tecnologias de redução ou prevenção à emissão de gases de efeito estufa; implementar programas nacionais de adaptação e mitigação às mudanças climáticas; cooperação em pesquisas científicas e tecnológicas; e a promoção da educação ambiental como meio conscientização pública com relação à mudança do clima (MINISTÉRIO DO MEIO AMBIENTE², 2020).

A Decisão 5 / CP.7 da sétima sessão da Conferência das Partes (COP 7) reconheceu as necessidades específicas e situações especiais dos países menos desenvolvidos, na medida em que são menos capazes de lidar com os efeitos adversos de mudanças climáticas e estabeleceu um programa de trabalho para os países menos desenvolvidos, que inclui: apoiar a preparação e implementação de políticas nacionais programas de ação de adaptação; fortalecer as já existentes e, quando necessário, estabelecer, secretarias nacionais de mudança climática; promoção de programas de conscientização pública; e o desenvolvimento e transferência de tecnologias $\left(\mathrm{UNFCCC}^{4}, 2020\right)$.

O Protocolo de Quioto, é considerado um dos principais documentos adotados no âmbito da CQNUMC, durante a terceira Conferência das Partes, que ocorreu em 1997 em Quioto, no Japão. Aberto à assinatura em 11 de dezembro de 1997, em um complexo processo de lançamento do Protocolo, entrando em vigor em 16 de fevereiro de 2005. Atualmente, existem 192 Partes no Protocolo de Kyoto (UNFCCC $\left.{ }^{5}, 2020\right)$.

\footnotetext{
${ }^{75}$ BRASIL. DECRETO No 2.652, DE $1^{\circ}$ DE JULHO DE 1998. Promulga a Convenção-Quadro das Nações Unidas sobre Mudança do Clima, assinada em Nova York, em 9 de maio de 1992. Brasília, Disponível em: http://www.planalto.gov.br/ccivil_03/decreto/d2652.htm. Acesso em: 25 mai. 2020
} 
Muito se fala no Protocolo de Quioto até os dias de hoje, constituindo um marco na regulação de normas quanto às mudanças climáticas, haja vista que até então não havia um acordo de cunho mais específico, que estabelecesse metas mais concretas a serem perquiridas. Tal Protocolo, definiu um processo a longo prazo, sendo o primeiro deles de 2008 a 2012, no qual acordou-se a necessidade de redução de emissão até chegar à marca de redução de 5,2\% a menos de emissões em relação ao índice global de 1990 (BIATO, 2005, p. 242).

As disposições mais rígidas se aplicavam ao grupo de países componentes do Anexo I do Protocolo. Para os demais países, isto é, aqueles que não fazem parte do Anexo I, que possuíam uma condição especial de desenvolvimento, estabeleceu-se que as medidas atribuídas deveriam equilibrar-se com o crescimento do país, contando com recursos financeiros e acesso a tecnologias.

Historicamente, portanto, a maior parcela de responsabilidade sempre foi maior exigida dos países desenvolvidos, dos quais esperava-se a assunção do papel de liderança e o posicionamento efetivo na tomada de decisões e implementação de políticas públicas, tendo em vista a maior facilidade de consecução das metas estabelecidas em razão da condições de estabilidade econômica que gozam.

No entanto, ao longo dos anos esse padrão mundial vem se alterando, de modo que países considerados de economia emergente anteriormente ou de menor potencial poluidor, hoje figuram em altas posições no ranking de poluição mundial. O Brasil, por exemplo, conforme aponta a revista Harvard Review of Latin America (2020) historicamente considerado um país em desenvolvimento, foi incluído como um dos maiores emissores de Gases de Efeito Estufa de acordo com dados divulgados pela UNEP em setembro de 2019. A partir de dados do Emissions Gap Report 2019, os quatro principais emissores (China, União Europeia, Índia e Estados Unidos da América) contribuem mais de $55 \%$ das emissões totais de GEE no período na última década, excluindo os dados de LUC (Land-Use Change ${ }^{76}$ ). Os membros do G20 contribuem com $78 \%$. China emite mais de um quarto (26\%) das emissões globais (excluindo-se a contagem por LUC).

Os Estados Unidos da América emitem 13 por cento das emissões globais de GEE, com um declínio gradual de Emissões de GEE de 0,1\% ao ano na última década, mas um aumento de 2,5\%

\footnotetext{
${ }^{76}$ LUC é uma sigla que se refere a Land-Use Change, e a sigla relaciona-se às atividades humanas, que por meio do uso da terra, mudança no uso da terra e atividades florestais afetam as mudanças nos estoques de carbono entre os reservatórios de carbono do ecossistema terrestre e entre o ecossistema terrestre e a atmosfera. Informações de "UNFCCC. Land Use, Land-Use Change and Forestry. Disponível em: https://unfecc.int/topics/landuse/workstreams/land-use--land-use-change-and-forestry-lulucf/land-use--land-use-change-and-forestry. Acesso em: 02 jun. 2020".
} 
em 2018 devido ao aumento demanda de energia. A União Europeia emite 8,5\% do GEE global e teve um declínio constante de $1 \%$ ao ano na última década e um declínio de 1,3\% em 2018. Índia, representa 7\% das emissões globais, e continua em um rápido crescimento das emissões de 3,7\% ao ano na década passada e 5,5\% em 2018. A Federação Russa $(4,8 \%)$ e Japão $(2,7 \%)$ são os próximos maiores emissores, com transporte internacional (aviação e expedição) representando cerca de 2,5\% das emissões de GEE. No entanto, o relatório prevê que se a contagem do estivesse LUC incluída, as emissões, os rankings mudariam, e o Brasil provavelmente seria o maior emissor (UNEP. 2019, p. 7).

Esse aumento no nível de emissão notavelmente maior do que na avaliação de 2018, relacionado ao uso da terra no Brasil, conforme aponta o relatório, encontra-se principalmente atrelado ao recente aumento de emissões históricas (desmatamento na Amazônia) e as incertezas políticas no país (UNEP, 2019, p. 12).

Assim, percebe-se que a grande divisão do mundo em dois grandes hemisférios, de Países Anexo I (considerados desenvolvidos), e Países não parte do Anexo I (considerados em desenvolvimento), conforme dispôs a Convenção Quadro das Nações Unidas sobre Mudança do Clima e o Protocolo de Quioto, não faz mais sentido na conjectura da sociedade internacional atual, tendo em vista que o ritmo de crescimento das economias mundiais sofreram grandes alterações ao longo dos anos, observando-se o aumento exponencial da emissão de poluentes em países anteriormente considerados de "terceiro mundo" ou de economia de baixo carbono.

\section{A AUTORRESPONSABILIDADE NO ACORDO DE PARIS A PARTIR DAS CONTRIBUIÇÕES NACIONALMENTE DETERMINADAS}

Dez anos após o Protocolo de Quioto, os avanços foram ínfimos em relação a expectativa que restava depositada na consecução das metas de redução de gases de efeito estufa, que se mostraram bem abaixo dos níveis pretendidos. Foi então que começou a ser discutido e repensado um Novo Acordo Global do Clima, que culminou na adoção do "Acordo de Paris" em novembro de 2015 durante a realização da COP 21 em Paris.

O Acordo de Paris, como ressaltam os apontamentos de Boisson de Chazournes (2017, p. 97) e Carl-Friedrich Schleussner (2016, p. 827) reflete a emergência do cenário mundial diante do 
atual contexto de mudanças climáticas e os níveis de emissões de gases de efeito estufa, vislumbrando o acordo como um instrumento capaz de mobilizar a sociedade internacional na busca pela mitigação dos impactos provenientes das mudanças climáticas.

O Acordo de Paris foi adotado durante a COP 21 em Paris, em 12 de dezembro de 2015, aberto à assinatura em 22 de abril de 2016 na sede da ONU em Nova York, entrando em vigor no plano internacional no dia 4 de novembro de 2016. Desde então, outros países ratificaram o Acordo, alcançando um total de 189 Partes (de 197 partes da Convenção) no primeiro semestre de 2020 $\left(\mathrm{UNFCCC}^{3}, 2020\right)$.

O documento inovou ao trazer as chamadas Contribuições Nacionalmente Determinadas (NDCs), onde cada Parte deve adotar medidas de mitigação domésticas, com o objetivo de alcançar os objetivos de suas próprias NDCs, levando em conta suas responsabilidades comuns, porém diferenciadas, dentro das circunstâncias nacionais de cada um. As Contribuições Nacionalmente Determinadas apontam para a importância da expansão das ferramentas domésticas de mitigação dos impactos das mudanças climáticas as quais deverão ser desenvolvidas no âmbito de cada um dos Estados-Partes.

O Acordo de Paris surge, neste sentido, como um divisor de águas na governança internacional voltada à mudança do clima por trazer uma proposta de abordagem diferenciada, que resgata mais uma vez o princípio da responsabilidade comum porém diferenciada, mas não divide o planeta em dois grandes polos, tampouco imputa o peso da responsabilidade exclusivamente às grandes potências mundiais, mas de fato, arroga a responsabilidade de cada qual conforme sua parcela de "culpabilidade" e capacidade contributiva. "Há claramente um dever de todas as partes de realizar ações para o clima" (NAÇÕES UNIDAS², 2020).

Os países desenvolvidos relatam o apoio que prestam, os países em desenvolvimento o apoio que recebem e precisam. As informações fornecidas por todas as Partes, sejam países desenvolvidos ou em desenvolvimento, sobre mitigação e suporte estão sujeitas a uma 'revisão de especialistas técnicos' e 'considerações facilitadoras e multilaterais do progresso' realizadas pelos órgãos científicos e de assessoramento da CQNUMC (RAJAMANI, 2016, p. 511-512).

O Acordo organiza uma estrutura diferenciada em relação ao modelo de negociações TopDown que vinha sendo adotado até então (conforme veremos adiante) com vistas a permitir atingir essas metas através da inclusão significativa de todos os Estados Partes. Como bem estabelece Patrícia Galvão Ferreira, o Acordo de Paris é o primeiro instrumento a apresentar provimentos 
autônomos para "assuntos como adaptação climática, perdas e danos, sumidouros e reservatórios de gases de efeito estufa, financiamento climático, desenvolvimento e transferência de tecnologia e capacitação" (FERREIRA, 2018, p. 666).

Assim, o Acordo de Paris elenca desde sua introdução essa ideia de responsabilidade singular de cada realidade nacional, "na prossecução do objetivo da Convenção, e sendo guiada por seus princípios, incluindo o princípio da igualdade e responsabilidades comuns, porém diferenciadas e respectivas capacidades, à luz das diferentes circunstâncias nacionais"77.

O artigo quarto, ademais, que guarda o pilar do Acordo de Paris, as chamadas Contribuições Nacionalmente Determinadas, propõe um instrumento de implementação das metas nunca antes utilizado por nenhum outro programa desenvolvido no âmbito da Convenção Quadro sobre Mudança do Clima, tendo em vista que não somente busca respeitar a individualidade da capacidade contributiva de cada Estado Parte, como também enseja o exercício da auto responsabilidade de cada país, em estabelecer suas próprias metas com base no contexto real nacional.

O referido dispositivo determina que "cada Parte deverá preparar, comunicar e manter sucessivas contribuições nacionalmente determinadas que pretendam alcançar". No escopo dessas contribuições, as Partes deverão buscar medidas domésticas de mitigação, visando alcançar os objetivos de contribuições assumidas. A UNFCCC aponta o instituto das Contribuições Nacionalmente Determinadas como o coração do Acordo de Paris e da consecução dos objetivos a longo prazo, tendo em vista que incorporam os esforços de cada país para reduzir as emissões nacionais e se adaptar aos impactos das mudanças climáticas (UNFCCC $\left.{ }^{1}, 2020\right)$.

Em suma, Patrícia Galvão Ferreira (2018, p. 666) refletiu bem o escopo do Acordo de Paris ao estabelecer as Contribuições Nacionalmente determinadas:

O Acordo de Paris inova igualmente, estabelecendo uma obrigação universal de os Estados empreenderem e comunicarem nacionalmente determinados contribuições climáticas e criando um sistema complexo de supervisão que inclui uma estrutura de transparência aprimorada, um inventário periódico de ação climática coletiva e um mecanismo para facilitar a implementação e promover a conformidade. Esses mecanismos de supervisão devem trabalhar juntos para incentivar ações climáticas ambiciosas.

\footnotetext{
${ }^{77}$ BRASIL. Decreto $\mathbf{n}^{\mathbf{0}}$ 9.073, de 5 de junho de 2017. Promulga o Acordo de Paris sob a Convenção-Quadro das Nações Unidas sobre Mudança do Clima, celebrado em Paris, em 12 de dezembro de 2015, e firmado em Nova Iorque, em 22 de abril de 2016. Brasília, Disponível em: http://www.planalto.gov.br/ccivil_03/_ato20152018/2017/decreto/D9073.htm. Acesso em: 25 mai. 2020.
} 
As Contribuições Nacionalmente Determinadas representam uma verdadeira mudança paradigmática de todo um regime de mudanças climáticas que vinha sendo adotado até então. Apesar dos temores quanto ao seu modo de execução, implementação e verificação, essa nova abordagem de administração de metas quantitativas de redução de gases de efeito estufa trazida pelo Acordo de Paris, buscou, além de respeitar as capacidades fáticas de cada parte, resgatar compromissos reais e fidedignos baseados em um contexto de confiança mútua e auto responsabilidade.

De modo geral, as contribuições nacionais baseiam-se em três princípios: "ambição" (pretendendo ultrapassar as previsões de redução de emissões de gases de efeito estufa de cada Estado até 2020); diferenciação (pelo princípio da responsabilidade comum, porém diferenciada, devem ser examinadas as circunstâncias nacionais de cada país); transparência (são publicados quando recebidos pelo secretariado no website da UNFCCC) de forma pública (AUBERTIN; KALIL, 2017).

Até o momento, 186 Estados enviaram sua primeira Contribuição Nacionalmente Determinada. O Secretariado mantém um registro público de todas as CNDs remetidas pelos Estados Partes do Acordo de Paris em uma plataforma online e facilmente acessível ao público externo, denominada "NDC Registry” (UNFCCC 2 , 2020).

\section{A DIFERENCIAÇÃO DA ABORDAGEM TOP-DOWN DAS CONTRIBUIÇÕES NACIONALMENTE DETERMINADAS EM RELAÇÃO AO PROTOCOLO DE QUIOTO}

Qual a garantia de que mesmo após tantos anos de tentativas de implementação do referido

protocolo, agora haverá um novo contexto de efetivação de normas através desta abordagem do Acordo de Paris? A principal linha argumenta a esse questionamento reside na abordagem bottomup trazida pelas Contribuições Nacionalmente Determinadas que a diferença da estrutura TopDown adotada até então no âmbito da CQNUMC, em especial no Protocolo de Quioto.

Como aponta o Professor de Relações Internacionais e Diretor de Pesquisa do Instituto de Pesquisa Grantham sobre Mudanças Climáticas e Meio Ambiente, Robert Falkner, para obter reduções de emissões a longo prazo, o Acordo de Paris exige às partes a apresentação regular de compromissos denominados contribuições determinadas nacionalmente (CNDs), e é essa dependência do voluntariado dos países como novo método de política climática que marca a saída 
mais significativa da abordagem do Protocolo de Quioto. Em vez de estabelecer um conjunto de emissões quantitativas acordadas internacionalmente, o Acordo de Paris contorna o conflito inerente às negociações do Protocolo de Kyoto, deixando aos países a incumbência de determinar individualmente quanto eles desejam contribuir para o esforço coletivo de mitigação (FALKNER, 2016, p. 10).

O autor aponta que a ruptura do Acordo de Paris em relação ao Protocolo de Quioto foi incluir todos os países em seu esforço de mitigação. Considerando que o Protocolo de Quioto impunha obrigações de redução de emissões somente ao Anexo I (países desenvolvidos), o novo acordo obriga todos os emissores a tomar medidas nacionais de implementação para limitar o aquecimento global (FALKNER, 2016, p. 11).

Além disso, as disposições quanto às metas quantitativas de redução eram adotadas de forma única para cada um desses blocos, assim como ocorria no protocolo de Quioto que estabelecia responsabilidades diferenciadas para os países componentes do Anexo I (países desenvolvidos) e países não-parte do Anexo I (países em desenvolvimento). Esse é um claro exemplo da abordagem “Top-Down”, isto é, o mandamento normativo vinha de uma normativa padrão e "superior" (Top) e que irradiava as disposições de modo padronizado e diretivo aos seus destinatários (Down). O que se viu ao longo dos anos foi uma série de descumprimento das normativas internacionais de regulamentação climática que aplicava esse modelo de incidência da norma.

As Contribuições Nacionalmente Determinadas, por sua vez, trazem um enfoque diferenciado. Primeiramente, conforme vimos, elas rompem com aquela segregação binária entre "países desenvolvidos" e "em desenvolvimento", para reconhecer as circunstâncias especiais de cada nacional à luz do princípio das responsabilidades comuns, porém diferenciadas, conforme vimos anteriormente.

Além disso, o Acordo de Paris, através das Contribuições Nacionalmente Determinadas utiliza a abordagem "Bottom-Up", onde as normas não são mandatoriamente definidas e inalteráveis por uma "normativa superior". Pelo contrário, os compromissos e as metas a serem alcançadas são definidos pelo próprio Estado (Bottom) que se obriga a cumpri-las perante a sociedade internacional, elaborando, comunicando e mantendo suas sucessivas contribuições nacionalmente determinadas, que são transformadas em um documento oficial e depositadas junto ao Secretariado para paulatino acompanhamento $(U p)$. 
Patrícia Ferreira enaltece a nova metodologia utilizada pelas CNDs, que agrega um “caráter híbrido", onde o Acordo de Paris carrega todas as nuances tradicionais de um tratado, mas que para sua consecução, utiliza uma ferramenta que depende do comprometimento e elaboração de documentos por cada Estado a partir de suas realidades nacionais (FERREIRA, 2018, p. 667).

Ramajani, por sua vez, ressalta que essa nova abordagem adotada pelo Acordo de Paris buscou abraçar um modelo de "autodiferenciação" limitada, ao permitir que as partes enviem suas 'contribuições pretendidas determinadas nacionalmente' no contexto de suas realidades internas. Ao enviar essas contribuições, as Partes puderam determinar o escopo de suas contribuições, sua forma, seu rigor e as informações que as acompanharão, escolhendo seus próprios compromissos de modo a adaptá-los às circunstâncias, capacidades e restrições nacionais, diferenciando-se de todas as outras nações, o que a autora exatamente denomina de "autodiferenciação" (RAJAMANI, 2016, p. 509-510).

Conforme preleciona Daniel Bodansky (2016, p. 303), o Acordo de Paris se diferencia do Protocolo de Quioto em quatro aspectos, primeiro, as Contribuições Nacionalmente Determinadas são determinadas nacionalmente e não negociadas internacionalmente; segundo, eles não são juridicamente vinculativos: não há obrigação sob o Acordo de Paris para alcançá-los; terceiro, eles devem ser registrados em um registro público, e não em um anexo ao Acordo; e quarto, eles são exigidos de todas as partes, e não apenas das partes do Anexo I.

De modo geral, as Contribuições Nacionalmente Determinadas revelam um aspecto híbrido, tratam-se de disposições que refletem as circunstâncias nacionais das Partes, mas que revelam o caráter vinculativo a partir do momento em que são assumidas internacionalmente pelos Estados e remetidas em documento oficial ao Secretariado da CQNUMC para registro geral.

\section{CONSIDERAÇÕES FINAIS}

O princípio das responsabilidades comuns, porém diferenciada, trata-se de instituto reconhecido desde os primeiros documentos internacionais de proteção climática. No entanto, como vimos, ao longo dos anos, a forma de aplicação do referido princípio ganhou novos contornos. A Convenção Quadro das Nações Unidas sobre Mudança do Clima dividia o mundo em dois grandes blocos, de países desenvolvidos e países em desenvolvimento. No entanto, com a 
evolução da sociedade internacional, vislumbrou-se a necessidade de reflexão da justiça climática com base na capacidade contributiva de cada Estado, bem como uma maior participação dos países em desenvolvimento.

Nesse contexto, surge o Acordo de Paris com uma nova abordagem do princípio das responsabilidades comuns, mas diferenciadas, com enfoque na capacidade das Partes à luz das diferentes circunstâncias nacionais, capturando uma forma inovadora de diferenciação em favor dos países em desenvolvimento e estendendo apoio financeiro, tecnológico e de capacitação. É esse compromisso de diferenciação e apoio que desamarrou o histórico nó górdio e abriu caminho para Paris.

De fato, a abordagem adotada no Acordo de Paris com a criação das "Contribuições Nacionalmente Determinadas" é bastante ousada, ainda que carregue uma logicidade simples, tendo em vista que, historicamente conforme vimos, as normativas voltadas à regulamentação das mudanças do clima assumia um modelo de responsabilização bipartido.

Conclui-se que na conjetura atual do regime internacional de mudanças climáticas, todos os países indistintamente possuem a reconhecida importância no processo de combate internacional dos efeitos às mudanças climáticas, cada qual assumindo a posição que lhe é cabível conforme o contexto nacional em que estão inseridos.

\section{REFERÊNCIAS}

AUBERTIN, Catherine; KALIL, Livia. La contribution du Brésil à la COP21 : l'agrobusiness du futur. Brésil(s), Paris, França, v. [s.i.], n. 11, On-Line, 16 mar. 2017. Disponível em: https://journals.openedition.org/bresils/2154\#text. Acesso em: 08 maio 2018.

BIATO, Márcia Fortuna. Convenção-quadro das Nações Unidas sobre mudança de clima. Revista de Informação Legislativa, Brasília, v. 42, n. 166, p. 233-251, abr./jun. 2005.

BRASIL. Decreto $n^{\circ} 2.652$, de $1^{\circ}$ de julho de 1998. Promulga a Convenção-Quadro das Nações Unidas sobre Mudança do Clima, assinada em Nova York, em 9 de maio de 1992. Brasília, Disponível em: http://www.planalto.gov.br/ccivil_03/decreto/d2652.htm. Acesso em: 25 maio 2020

BRASIL. Decreto n ${ }^{\circ}$ 9.073, de 5 de junho de 2017. Promulga o Acordo de Paris sob a Convenção-Quadro das Nações Unidas sobre Mudança do Clima, celebrado em Paris, em 12 de dezembro de 2015, e firmado em Nova Iorque, em 22 de abril de 2016. Brasília, Disponível em: http://www.planalto.gov.br/ccivil_03/_ato2015-2018/2017/decreto/D9073.htm. Acesso em: 25 maio 2020. 
BODANSKY, Daniel. The Paris Climate Change Agreement: A New Hope? Washington: American Journal of International Law. [s.i.] v. 1, n.288. Abril 2016

BOISSON DE CHAZOURNES, Laurence. Regards sur l'Accord de Paris - Un accord qui bâtit le futur. In: Torre-Schaub, M. \& Delmas-Marty M. Bilan et perspectives de l'Accord de Paris (COP 21) - Regards croisés. Paris : IRJS Editions, 2017. P. 97-106.

European Comission. UNFCCC - United Nations Framework Convention on Climate Change. Disponível em: https://ec.europa.eu/knowledge4policy/organisation/unfccc-unitednations-framework-convention-climate-change_en. Acesso em: 25 maio 2020.

FALKNER, Robert. The Paris Agreement and the new logic of international climate politics. Oxford: International Affairs (oxford University Press), v. 92, n. 5, p. 1107-1125, ago. 2016.

FERREIRA, Patricia GalvÃo. The Paris Agreement on Climate Change: Analysis and Commentary. Oxford: Canadian Yearbook Of International Law/annuaire Canadien de Droit International, [s.1.], v. 55, p.666-672, 3 set. 2018. Cambridge University Press (CUP).

HUQ, Saleemul; REID, Hannah; KONATE, Mama; RAHMAN, Atiq; SOKONA, Youba; CRICK, Florence. Mainstreaming adaptation to climate change in Least Developed Countries (LDCs). Climate Policy, Online, v. 4, n. 1, p. 25-43, jun. 2011.

KHOR, Martin. Climate Change, Technology and Intellectual Property Rights: Context and Recent Negotiations. Research Paper, South Centre. 2012. p. 6.

Ministério do Meio Ambiente ${ }^{1}$. Linha do tempo das medidas envolvendo Mudanças Climáticas. Disponível em: https://www.mma.gov.br/component/k2/item/15164-linha-do-tempodas-medidas-envolvendo-mudan\%C3\%A7as-clim\%C3\%A1ticas.html. Acesso em: 20 maio 2020.

Ministério do Meio Ambiente ${ }^{2}$. Compromissos Estabelecidos na Convenção-Quadro das Nações Unidas sobre Mudança do Clima (UNFCCC). Disponível em: https://www.mma.gov.br/quem-\%C3\%A9-quem/item/15142-contribui\%C3\%A7\%C3\%B5espara-o-documento-base.html. Acesso em: 25 maio 2020.

Ministério do Meio Ambiente ${ }^{3}$. Convenção-Quadro das Nações Unidas sobre Mudança do Clima (UNFCCC). Disponível em: https://www.mma.gov.br/clima/convencao-das-nacoesunidas. Acesso em: 25 maio 2020.

MIYAN, M. Alimullah. Droughts in Asian Least Developed Countries: vulnerability and sustainability. Weather And Climate Extremes, [s.1.], v. 7, p. 8-23, mar. 2015. Elsevier BV.

MOTTA, Ronaldo Seroa da; HARGRAVE, Jorge; LUEDEMANN, Gustavo; GUTIERREZ, Maria Bernadete Sarmiento (ed.). Mudança do Clima no Brasil: aspectos econômicos, sociais e regulatórios. Brasília: Ipea, 2011. 
NAÇÕES UNIDAS ${ }^{1}$. Conferência das Nações Unidas sobre Mudança Climática. Disponível em: https://nacoesunidas.org/cop21/. Acesso em: 29 maio 2020.

NAÇÕES UNIDAS ${ }^{2}$. ONU esclarece dúvidas a respeito do novo acordo climático adotado pelos Estados-membros na COP21. Disponível em: https://nacoesunidas.org/onu-esclareceduvidas-a-respeito-do-novo-acordo-climatico-adotado-pelos-estados-membros-na-cop21/. Acesso em: 02 jun. 2020.

PATT, A. G.; TADROSS, M.; NUSSBAUMER, P.; ASANTE, K.; METZGER, M.; RAFAEL, J.; GOUJON, A.; BRUNDRIT, G. Estimating least-developed countries' vulnerability to climaterelated extreme events over the next 50 years. Proceedings Of The National Academy Of Sciences, [s.1.], v. 107, n. 4, p. 1333-1337, 5 jan. 2010. Proceedings of the National Academy of Sciences.

RAJAMANI, Lavanya. AMBITION AND DIFFERENTIATION IN THE 2015 PARIS AGREEMENT: INTERPRETATIVE POSSIBILITIES AND UNDERLYING POLITICS. Cambridge: International And Comparative Law, v. 65, n. 2, p.493-514, 16 mar. 2016. Cambridge University Press (CUP).

REVISTA - HARVARD REVIEW OF LATIN AMERICA. Why is Brazil "Underdeveloped" and What Can Be Done About It? Disponível em: https://revista.drclas.harvard.edu/book/whybrazil-underdeveloped-and-what-can-be-done-about-it. Acesso em: 02 jun. 2020.

SCHLEUSSNER, Carl-friedrich et al. Science and policy characteristics of the Paris Agreement temperature goal. Nature Climate Change, Basingstoke, v. 6, n. 9, p.827-835, 25 jul. 2016.

UNEP. The Emissions Gap Report 2019. Nairobi: United Nations Environment Programme (UNEP), 2019.

UNFCCC ${ }^{1}$. Nationally Determined Contributions (NDCs): The Paris Agreement and NDCs. Disponível em: https://unfccc.int/process-and-meetings/the-paris-agreement/nationallydetermined-contributions-ndcs. Acesso em: 10 jan. 2020.

UNFCCC ${ }^{2}$. NDC Registry. Disponível em: https://www4.unfccc.int/sites/NDCStaging/Pages/All.aspx. Acesso em: 02 jun. 2020.

UNFCCC $^{3}$. Paris Agreement - Status of Ratification. Disponível em: https://unfccc.int/process/the-paris-agreement/status-of-ratification. Acesso em: 20 jan. 2020.

$\mathrm{UNFCCC}^{4}$. Synthesis report on the national adaptation programme of action process, including operation of the Least Developed Countries Fund. Disponível em:

https://www.uncclearn.org/sites/default/files/inventory/unfccc115.pdf. Acesso em: 25 maio 2020.

UNFCCC $^{5}$. What is the Kyoto Protocol? Disponível em: https://unfccc.int/kyoto_protocol. Acesso em: 31 maio 2020. 


\title{
THE PARIS AGREEMENT AND THE PARADIGMATIC CHANGE IN APPLICATION OF THE COMMON RESPONSIBILITY PRINCIPLE, BUT DIFFERENTIATED
}

\begin{abstract}
With the evolution of the international context of climate regulation, the international society realized that the bipartite model of accountability adopted until then did not reflect the maxim of the "principle of common, but differentiated responsibility". In this context, the present study analyzes how the Paris Agreement brings an innovative approach based on the institution of Nationally Determined Contributions that reflects the national circumstances of each Party. It uses exploratory and bibliographic research as methodological procedures, with consultation in printed and electronic media. Furthermore, the research is of a qualitative type, which aims to analyze the subjective aspect of the theme, seeking to investigate it from a more critical perspective. We conclude that it was necessary to change the traditional paradigm of the international climate regime for an effective inclusion of all members of international society in the context of mitigating the effects of climate change.
\end{abstract}

Keywords: Differentiated responsibility. Climate changes. Paris Agreement. 